XXIII.

\title{
Das Problem der Möglichkeit der Zurückfïhrung bestimmter intrauterin entstehender Missbildungen auf das Versagen gewisser mütterlicher oder auch fötaler Inkretionsorgane.
}

Von

Emil Abderhalden Halle a. S.

Gudernatseh hat gezeigt, dass es geingt, Kaulquappen durch Verabreichung von Sehilddrüse und von Thymus im Wachstum in charakteristischer Weise zu beeinflussen. Romeis bestätigte diese Beobachtungen und erweiterte sie. Es gelang mir, an einem sehr grossen Materiale von Kaulquappen zu zeigen, dass die Organe dureh die aus ihnen darstellbaren $A b$ bauprodukte und ferner durch aus ihnen gewonnene Extraktivstoffe zu ersetzen sind $^{\mathbf{1}}$ ). Dadurch ist das Studium der Wirkung bestimmter Inkrete auf das Wachstum und auf den Organismus überhaupt auf eine neue Basis gestellt worden. Es ist nunmehr möglich, verschiedene Inkrete in bestimmten Mengen zu kombinieren. Bei derartigen Versuchen wurde beobachtet, dass es sehr leicht gelingt, Missbildungen zu erzeugen. Dieselbe Beobachtung wurde auch an Axoloteln gemacht. Man erhält, wie an anderer Stelle durch Abbildungen belegt werden wird, zum Teil ganz abenteuerliche Formen: Entwicklungshemmungen, Störung der Rüekbildung, überstürzte Rückbildung, Hypo- und Hyperplasien usw. Der grösste Teil der hier erwähnten Feststellungen ist noch nicht mitgeteilt und bezieht sich auf Versuche an ca. 10000 Versuchstieren.

Diese Beobachtungen gaben der Vermutung, dass vielleicht manche uterin entstehende Missbildung ihre Entstehung einem Versagen von Inkretionsorganen verdankt, eine bestimmte Unterlage. Es ist möglieh, dass ein Defekt solcher Organe im mütterlichen Organismus auf den Fötus in bestimmter Weise einwirkt. Es ist jedoch auch denkbar, dass fötale Inkretionsorgane in ihrer Anlage und Funktion versagen und so zu Störungen bestimmter Art führen. Ich denke dabei nicht nur an äusserlich sichtbare körperliche. Entwicklungsstörungen, sondern auch an solehe der geistigen

1) Vgl. Emil Abderhalden, Pflügers Archiv. Bd.162. S.99. 1915. (Hier ist auch die einschlägige Literatur zitiert.) 
Das Problem der Zurückführung infrauterin entstehender Missbildungen. 507

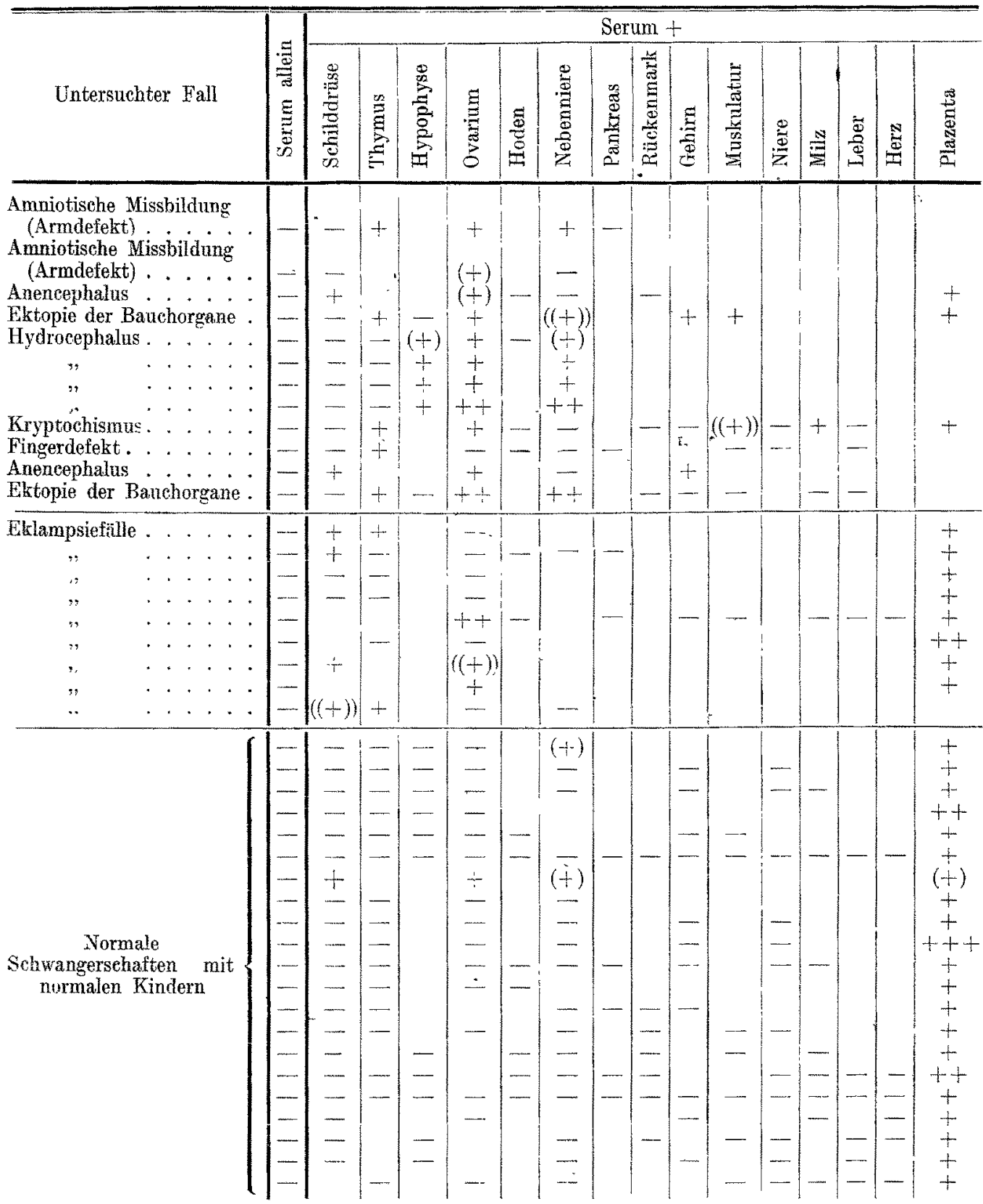


und psychischen Funktionen. Selbstverständlich muss auch der väterliche Organismus in den Kreis der Betrachtungen gezogen werden.

Leider hält es zurzeit in vielen Fällen sehr schwer, eine ausreichende Funktionsprüfung der Inkretionsorgane vorzunehmen, wenn eine Missbildung, für die mechanische Ursachen nicht in Frage kommen, geboren wird. Seit einer Reihe von Jahren ist hier das Blutserum von Frauen, die solche Missbildungen zur Welt gebracht haben, auf Abwehrfermente geprüft worden, um auf diesem Wege einen Einblick in etwaige Störungen zu erhalten. Ich verdanke Herrn Kollegen Veit die meisten der einschlägigen Fälle. Selbstverständlich urden daneben stets zahlreiche Fälle mit untersucht, bei denen gesunde Kinder geboren worden waren. Die vorstehende Uebersicht gibt die erhaltenen Resultate wieder.

Leider ist die Zahl der untersuchten Fälle zuzeit viel zu gering, um ein abschliessendes Urteil fällen za hỏnnen. Auffallend ist das regelmässige Vorhandensein von auf bestinmte Inkretionsorgane eingestellten Abwehrfermenten, in jenen Fällen, in denen Missbildangen geboren worden waren, während bei jenen Frauen, die normale Kinder zur Welt gebracht hatten, nur hier und da solche Fermente zugegen waren.

Mir scheint, dảss man derarige Untersuchungen fortsetzen sollte. Dabei müssten die erhaltenen Ergebnisse sich nicht nur auf die Betrachtung des. eben geborenen Kindes beziehen, sondern es müsste sein Schicksal weiter verfolgt werden. Ein als normal e klärtes Kind kann sich später als durchaus nicht normal herausstellen. WS wäre gewiss von grösster Bedeutung für die Auffassung marsher Defekte körperlicher und geistiger Art, wenn die erwähnte Möglichkeit von Wechselbeziehungen sich allgemein und. sicher nachweisen liesse. Der Physiologe vermag in solchen Fragen nur wenig beizutragen, weil ihm die Möglichkeit fehlt, die einschlägigen Fälle selbst zu beobachten und weiter zu verfolgen. Bei Versuchstieren mit gestörten Inkretionsorganen handelt es sich wohl immer um Zustände, die den ganzen Organismus in weitgehender Weise in Mitleidenschaft gezogen haben, während wir beim Menschen offenbar ein viel mannigfaltigeres Bild der gestörten Inkretion mit feinsten Abstufungen vorfinden. Diesen Feinheiten nachzugehen, ist die Aufgabe der Zukunft. Selbstverständlich' sind wir uns der grossen Schwierigkeiten des ganzen Problems voll bewusst. Es ist z. B. leicht möglich, dass eine Störung eines oder mehrerer Inkretionsorgane am Anfange der Schwangerschaft vorhanden ist, und ihre Wirkung entfaltet, während bei der Geburt diese schọn längst verschwunden ist. Nur ein sehr grosses Material kann darüber Auskunft geben, wie oft Störungen auf dem Gebiete bestimmter Inkretionsorgane bei der Mutter oder dem Vater schon beim Fötus dessen Entwicklung beeinflusst. Es scheint mir der Mühe wert, diesen Möglichkeiten mehr Aufmerksamkeit zu widmen, als es bis jetzt der Fall war. 